\title{
Heterogeneity of the Ro/SSA Antigen \\ Different Molecular Forms in Lymphocytes and Red Blood Cells
}

Michael D. Rader, Charles O'Brien, Yunshang Liu, John B. Harley, and Morris Reichlin

Arthritis/Immunology Program, Oklahoma Medical Research Foundation, Oklahoma City, Oklahoma 73104; Veterans Administration

Medical Center, Oklahoma City, Oklahoma 73104; and Departments of Medicine and Microbiology, University of Oklahoma

Health Sciences Center, Oklahoma City, Oklahoma 73190

\begin{abstract}
Ro(SSA) is an intracellular ribonucleoprotein against which autoantibodies are found in a portion of patients with Sjögren's syndrome and systemic lupus erythematosus. A form of Ro(SSA) is described in red blood cells that shares a line of identity with purified Ro(SSA) from bovine spleen and human lymphocytes in counterimmunoelectrophoresis, but has different molecular properties. Ro(SSA) from red blood cells exists in association with only two small RNAs as opposed to four in other cell types, as determined by RNA extraction of protein A-assisted immunoprecipitates. In addition to the common 60-kD Ro(SSA) protein, Western blot analysis revealed an additional 52-kD protein in lymphocytes and a 54-kD protein in red blood cells. The $60-\mathrm{kD}$ form of $\mathrm{Ro}(\mathrm{SSA})$ in red cells was found to be antigenically distinct from that in the lymphocyte, because sera were identified that bound each exclusively. Finally, a rabbit antibovine Ro(SSA) serum distinguished red cell from lymphocyte Ro(SSA). These results suggest two distinctive populations of $\operatorname{Ro}(\mathrm{SSA})$ proteins and distributions of Ro(SSA) RNAs in the lymphocyte and red blood cell.
\end{abstract}

\section{Introduction}

Systemic lupus erythematosus (SLE) and Sjögren's syndrome $(\mathrm{SS})^{1}$ are diseases of unknown etiology and uncertain pathogenesis. A common characteristic of these diseases is the production of autoantibodies, among which anti-Ro(SSA) is found in both conditions. Using sensitive ELISA methodology, elevated levels of anti-Ro(SSA) have been detected in $49 \%$ of SLE patients and up to $96 \%$ of SS patients $(1,2)$.

In nucleated human cells, Ro(SSA) has been described as a 60-kD protein associated with one of four RNAs of 83-112 bases, termed hY RNAs $(3,4)$. This particle of unknown function is detected and affinity purified using isolated IgG from patients with SLE and SS. Initially, Ro(SSA) and its antibody have been defined solely on the basis of gel diffusion (Ouchterlony) using monospecific prototype serum. Now, in

Address reprint requests to Dr. Morris Reichlin, Arthritis and Immunology Laboratories, Oklahoma Medical Research Foundation, 825 Northeast 13th Street, Oklahoma City, OK 73104.

Received for publication 9 September 1988 and in revised form 1 December 1988.

1. Abbreviations used in this paper: RNP, ribonucleoprotein; SS, Sjögren's syndrome.

J. Clin. Invest.

(c) The American Society for Clinical Investigation, Inc. $0021-9738 / 89 / 04 / 1293 / 06 \$ 2.00$

Volume 83, April 1989, 1293-1298 addition to the serological definition, the association of the Ro(SSA) protein with hY RNAs has been used as a characteristic property $(3,4)$. Ro(SSA) has been described in several human tissues and tissues from lower animals using several different techniques (4-9). Whereas differences have been found in the structure and quantity of Ro(SSA) across species barriers $(4,5,8)$, molecular differences have not previously been described between Ro(SSA) from different tissues and cell types in the same species (4). In this report we describe structural differences in Ro(SSA) obtained from human lymphocytes and red blood cells.

\section{Methods}

Cell samples and separation. Human blood cells were isolated from fresh heparinized blood samples from healthy donors using the procedure accompanying Histopaque-1077 (Sigma Chemical Co., St. Louis, MO). Lymphocytes were obtained in the top layer and frozen in liquid nitrogen for viability in freezing media (RPMI 1640; Irvine Scientific, Santa Ana, CA) $+20 \%$ AB serum $+7.5 \%$ DMSO $+1 \%$ penicillin/ streptomycin $+1 \%$ L-glutamine). For some of the experiments, lymphocytes were obtained from leukophoresis of a patient with chronic lymphocytic leukemia. Lymphocyte-depleted red blood cells were washed three times by adding an equal volume of PBS and centrifuging at $500 \mathrm{~g}$ for $10 \mathrm{~min}$. After each wash, the buffy coat was removed to further deplete the red cells of contaminating granulocytes. Granulocytes were isolated using hydroxy-ethylstarch, Hespan (American Hospital Supply, Irvine, CA), and Ficoll-Hypaque with Percoll (Pharmacia Fine Chemicals, Uppsala, Sweden), which has been described elsewhere (10). The red cells were packed at a concentration of $8 \times 10^{6}$ cells $/ \mathrm{mm}^{3}$ by centrifugation at $500 \mathrm{~g}$ for $20 \mathrm{~min}$ after the last wash. They were stored at $-30^{\circ} \mathrm{C}$, packed, and overlayered with PBS.

Lysate preparation. Lymphocytes were thawed and the DMSO was immediately diluted out in $10 \mathrm{vol}$ of PBS. The cells were pelleted to a concentration of $10^{6}$ cells $/ \mathrm{mm}^{3}$ by centrifugation at $500 \mathrm{~g}$ for $5 \mathrm{~min}$. Granulocytes were used freshly isolated and pelleted by centrifugation at $500 \mathrm{~g}$ for $5 \mathrm{~min}$. Because isolated red cells were frozen packed in large volumes $(50 \mathrm{ml})$, small aliquots were obtained by using an Ouchterlony well punch to core sample the frozen packed cells. Lysis was achieved by adding 2 vol of either distilled water if the lysate was to be used immediately, $0.1 \mathrm{mM}$ DTT (Pharmacia Fine Chemicals) PMSF (Sigma Chemical Co.) if the lysate was to be processed first, or NET-2 buffer ( $50 \mathrm{mM}$ Tris- $\mathrm{HCl}, 150 \mathrm{mM} \mathrm{NaCl}, 0.05 \% \mathrm{NP}-40, \mathrm{pH} 7.4$ ) if the lysate was to be used for immunoprecipitation. These lysate solutions were then sonicated on ice with a sonifier (model 185; Branson Sonic Power, Danbury, CT) on setting 5 for $1 \mathrm{~s} / \mathrm{ml}$ bursts until total lysis was achieved as determined by microscopic examination. The soluble fraction of the lysate was obtained by pelleting the debris at $40,000 \mathrm{~g}$ for $30 \mathrm{~min}$ and using the supernatant.

$F(a b)_{2}^{\prime}$ preparation. $\mathrm{F}(\mathrm{ab})_{2}^{\prime}$ fragments of isolated IgG $(11)$ were prepared by a pepsin digestion method $(12,13)$ from the sera of SLE patients with monospecific antibodies, as determined by immunodiffusion and direct ELISA (14). Monospecificity means that only a single precipitin was present (e.g. anti-Ro/SSA, anti- $U_{1} R N P$, etc.), and that only one specificity was detectable by ELISA with affinity-purified 
antigens. Anti-Ro(SSA) IgG did not contain anti-La/SSB, anti- $\mathrm{U}_{1}$ ribonucleoprotein (RNP), or anti-Sm specificity by ELISA, nor did the anti- $\mathrm{U}_{1} \mathrm{RNP}$ IgG contain ELISA activity with $\mathrm{La} / \mathrm{SSB}, \mathrm{Ro} / \mathrm{SSA}$, or Sm coated plates. Briefly, $10 \mathrm{mg} / \mathrm{ml}$ pepsin (Sigma Chemical Co.) in $0.2 \mathrm{M}$ sodium acetate buffer $\mathrm{pH}$ (4.2) was added to isolated $\mathrm{IgG}$ at $4 \mathrm{mg} / \mathrm{ml}$ in $0.2 \mathrm{M}$ sodium acetate buffer at $\mathrm{pH} 4.2$ until the $\mathrm{IgG}$ pepsin weight ratio was $50: 1$. The reaction mixture was incubated at $37^{\circ} \mathrm{C}$ for $24 \mathrm{~h}$, after which pepsin was inactivated by dialysis against $0.02 \mathrm{M}$ Tris, $0.15 \mathrm{M}$ $\mathrm{NaCl}$, pH 7.2 using a 3,500-D cutoff dialysis membrane (Spectrum Medical, Los Angeles, CA). The concentration of $\mathrm{F}(\mathrm{ab})_{2}^{\prime}$ was determined using an extinction coefficient of 1.5 optical density units at 280 $\mathrm{nm} / \mathrm{mg}$ per $\mathrm{ml}$.

Sandwich enzyme-linked immunosorbent assay. This assay was developed to detect specific antigens in crude cell extracts. $F(a b)_{2}^{\prime}$ from the IgG of a patient with monospecific antibody is diluted in carbonate coating buffer ( $\mathrm{pH} 9.6$ ) and used to coat a 96-well microtiter plate (Costar Corp., Cambridge, MA) with $50 \mu$ l per well. The concentration of $F(a b)_{2}^{\prime}$ used was adjusted to give maximum sensitivity with minimum nonspecific background, which was highly dependent on the patient source of IgG. The concentrations used varied between 2-10 $\mu \mathrm{g} / \mathrm{ml}$. The primary antibody was incubated on the plate overnight at $4^{\circ} \mathrm{C}$. The remaining protein binding sites were blocked with $0.2 \mathrm{ml} /$ well of $0.1 \%$ gelatin in PBS Tween $20(0.05 \%)$ (blocking buffer) for 30 min at room temperature. The wells were washed three times with PBS and $0.05 \%$ Tween 20 (washing buffer). Cell lysates were used as antigen sources and dilutions made in blocking buffer. Each sample $(0.05 \mathrm{ml})$ was incubated in each well for $2 \mathrm{~h}$ at room temperature. The wells were again washed three times with washing buffer. A secondary antibody (monospecific composed of an antiserum preabsorbed with $\mathrm{F}(\mathrm{ab})_{2}^{\prime}$ from Cohn fraction II (Sigma Chemical Co.) at a concentration of 0.1 $\mathrm{mg} / \mathrm{ml}$ ) was added at 1:1,000 dilution in blocking buffer and incubated at room temperature for $2 \mathrm{~h}$. After another wash step, $0.05 \mathrm{ml}$ of an $\mathrm{F}_{\mathrm{c}}$-specific goat anti-human IgG alkaline phosphatase conjugate (Jackson Immunolabs, West Grove, PA) was added at the recommended dilution $(1: 6,000)$ in blocking buffer and incubated at room temperature for $2 \mathrm{~h}$. The wells were washed once more as before and $0.05 \mathrm{ml}$ of the enzyme substrate $p$-nitrophenyl phosphate was added to each well. Chromophore development was followed at $405 \mathrm{~nm}$ with an microelisa auto reader (MR 580; Dynatech Laboratories, Alexandria, VA). Plates were normalized by dividing the optical density of each well by the optical density achieved by a 1:200 dilution of a standard lymphocyte lysate reacting with a fixed dilution of a standard serum. This number varied from 0.8 to 1.2 .

RNA extraction of immunoprecipitates. The immunoprecipitation and subsequent extraction of RNAs from ribonucleoprotein autoantigens described previously (15) was used.

Cation exchange chromatography. Cation exchange beads (CM-52; Whatman Instruments, Kent, England) were swelled and equilibrated with $0.02 \mathrm{M}$ phosphate buffer ( $\mathrm{pH} \mathrm{6.0)}$ as described by the manufacturer. The beads were centrifuged at $500 \mathrm{~g}$ for $5 \mathrm{~min}$ and the excess buffer aspirated. 5 vol of CM- 52 were mixed with 1 vol of the supernatant of a crude, freshly made cellular lysate. After complete mixing, the beads were centrifuged as before. The extract, now cleared of hemoglobin and other basic proteins, was obtained by aspirating the supernatant.

SDS-PAGE. $10 \%$ polyacrylamide gels with $4.5 \%$ polyacrylamide stacking gels, both with $0.1 \%$ SDS were run using the discontinuous buffer method previously described (16).

Western immunoblotting. A method described previously $(17,18)$ was modified to use with a semidry blotting apparatus (American Bionetics, Emeryville, CA). The nitrocellulose was stained with fast green (Bio-Rad Laboratories, Richmond, CA) $0.1 \%$ in $20 \%$ methanol and $10 \%$ acetic acid. With the protein in the lanes visible, the lanes were cut into 2-mm-wide strips and incubated in 12-well trays (Dynatech Laboratories). Remaining protein attachment sites were blocked either overnight at $4^{\circ} \mathrm{C}$ or $30 \mathrm{~min}$ at room temperature with $5 \%$ nonfat dry milk made in Tris-buffered saline $(0.01 \mathrm{M}$ Tris- $\mathrm{HCl}, \mathrm{pH} 8.0,0.15$ $\mathrm{M} \mathrm{NaCl}$ ) and $0.05 \%$ Tween 20. An anti-human IgG alkaline phos- phatase conjugate (Promega Biotec, Madison, WI) was used diluted $1: 7,500$ in TBST to detect IgG binding to protein on the nitrocellulose by incubating at room temperature for $30 \mathrm{~min}$, after which an nitroblue tetrazolium 5-Bromo-4-chloro-3-indolyl phosphate substrate was used to detect binding of the conjugate.

Elution of affinity-purified antibody from nitrocellulose. Protein that had been run on polyacrylamide gels and blotted was incubated with antisera as in the Western blot procedure. The method for the elution of antibodies has been described $(19,20)$. The eluate was dialyzed to PBS by repeated dilution and concentration using the concentration device as recommended by the manufacturer (Centriprep; Amicon Corp., Danvers, MA).

Counterimmunoelectrophoresis was performed as previously described (21).

\section{Results}

Using a sensitive sandwich ELISA, Ro(SSA) was detected in lysates prepared from isolated red cells and lymphocytes. Lymphocytes isolated from normal individuals and a patient with chronic lymphocytic leukemia were found to have the same properties. The optical density obtained was inhibitable by more than $50 \%$ by preincubation of the secondary antibody with $0.1 \mathrm{mg} / \mathrm{ml}$ of affinity-purified bovine Ro(SSA) described previously (14). To address the possibility of lymphocyte contamination, a nRNP/Sm sandwich ELISA was developed to detect $\mathrm{nRNP}$ and Sm antigens in crude lysates. IgG from a patient with anti- $U_{1} R N P$ precipitins was isolated and $\mathrm{Fab}_{2}$ was prepared as described in Methods. This IgG trapped only $\mathrm{U}_{1} \mathrm{RNP}$, as only sera of this specificity were positive, whereas sera with anti-Ro/SSA, anti-La/SSB, or anti-Sm specificities gave no signal with such a sandwich assay. By comparing the optical density of standard dilutions of red cell (1:9) and lymphocyte (1:200) lysates using both assays, we were able to determine the amount of lymphocyte contamination using the $\mathrm{nRNP} / \mathrm{Sm}$ assay and compare that with the amount of Ro(SSA) detected. If the Ro(SSA) in the red cell were caused by lymphocyte contamination, lysates that showed equivalent chromophore development in the Ro(SSA) assay should be equivalent in the $\mathrm{nRNP} / \mathrm{Sm}$ assay. The standard dilutions were chosen to show an equivalent optical density for both cell lysates with the Ro(SSA) assay. When these standard dilutions were used in the $\mathrm{nRNP} / \mathrm{Sm}$ assay, essentially no $\mathrm{nRNP} / \mathrm{Sm}$ was detected in the red cell lysate compared with the lymphocyte lysate (Fig. 1). The relative paucity of the nRNP and Sm antigen in the anucleated red cell is not surprising and is probably an indication of residual lymphocyte contamination or background reactivity at the lower limits of the assay. The 20 -fold greater relative amount of $\operatorname{Ro}(\mathrm{SSA})$ detected in red

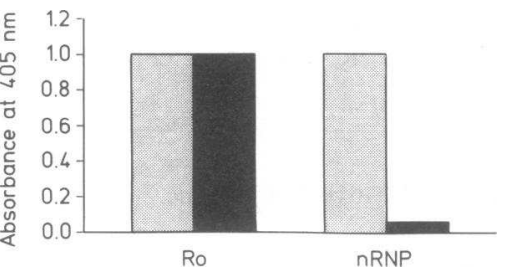

Figure 1. The solid (lymphocytes) and cross-hatched (red blood cell) bars on the left show the $\mathrm{OD}_{405 \mathrm{~nm}}$ of lymphocyte lysate $(1: 200)$ and red cell lysate (1:9), respectively, using a Ro(SSA) sandwich ELISA. The same two lysates on the right are used in a nRNP/Sm sandwich ELISA. 
cells supports the presence of $\operatorname{Ro}(\mathrm{SSA})$ in the red cell population. To rule out the possibility of granulocyte contamination in our red cell preparations, we compared the measurable Ro(SSA) from granulocytes and red cells. On a volume basis, the granulocyte lysate had less Ro(SSA) by ELISA than the red cell lysate. These results further support the presence of Ro(SSA) in the red cell population of blood cells.

By counting the cells used to make the lysates, the number of lymphocytes that would produce a lysate of a particular optical density could be calculated and compared with the number of red cells that would produce a lysate having a similar optical density by ELISA. The amount of lymphocyte contamination necessary to account for $\mathrm{Ro}(\mathrm{SSA})$ in the red cell lysate was found to be $0.41 \%$. Before separation, the percentage of lymphocytes in blood when compared with red cells is $0.07 \%$. This means that a sixfold enrichment of lymphocytes in whole blood would be necessary to explain the results on the basis of contamination. This calculation further bolsters our contention that the Ro(SSA) measured in red cell extracts derives from red cells and cannot be accounted for by either lymphocyte or granulocyte contamination.

RNA extraction of protein A-assisted immunoprecipitates showed Ro(SSA) in red cells is associated with two populations of hY RNAs (Fig. 2). Others have described four hY RNAs in nucleated cells; hY1, hY3, hY4, and hY5 (hY2 is a truncated form of hY1) (4, 20). One of the Ro(SSA)-associated RNA species in red cells migrates between hY1 and hY2; the other comigrates with hY4. Whether these RNAs are identical remains to be determined. In red cell lysates contaminated with lymphocytes, faint hY3 and hY 5 bands were detectable. These data firmly establish that the Ro(SSA) in the red cell lysate did not derive from lymphocyte or other leukocyte contamination.

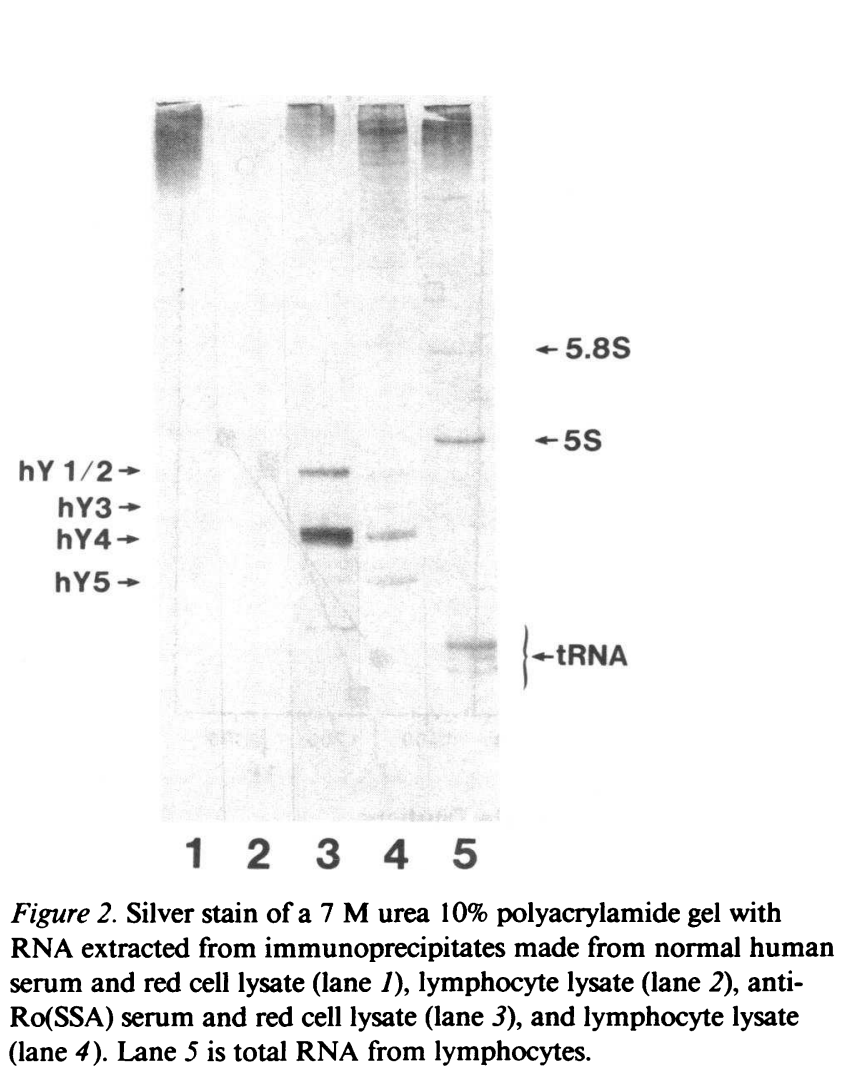

Figure 2. Silver stain of a $7 \mathrm{M}$ urea $10 \%$ polyacrylamide gel with RNA extracted from immunoprecipitates made from normal human serum and red cell lysate (lane 1), lymphocyte lysate (lane 2), antiRo(SSA) serum and red cell lysate (lane 3 ), and lymphocyte lysate (lane 4). Lane 5 is total RNA from lymphocytes.
The ratio of red cell to lymphocyte lysate that resulted in equivalent amounts of $\mathrm{Ro}(\mathrm{SSA})$ as detected by native assays (ELISA, immunodiffusion, RNA immunoprecipitation) was 30-60:1. Red cell Ro(SSA) antigenicity in assays reflecting native structure (ELISA, gel diffusion, immunoprecipitation) was unstable and activity was lost with any preparative maneuver.

Different results were obtained when Western immunoblots of reduced CM-52 extracts were run on SDS-polyacrylamide gels. Here, equal amounts of lymphocyte and red cell extracts yielded equivalent signals with serum samples that contained antibodies that reacted with $\mathrm{Ro}(\mathrm{SSA})$ from both sources. In addition to this difference in antigenicity reflecting assays of native and denatured forms, somewhat different molecular weight proteins were detected using lymphocyte and red cell extracts. Monospecific autoimmune sera, all of which gave a $\mathrm{Ro}(\mathrm{SSA})$ precipitin line in gel diffusion with bovine spleen extracts, reacted with 60 - and 54-kD forms from human red cell lysates, whereas human lymphocyte lysates showed 60and 52-kD forms (Fig. 3). The specificity of these antigenically active proteins was demonstrated by the lack of reactivity with other anti-Ro(SSA) sera (Fig. 4). As can be seen, serum Wa binds the lymphocyte $60-\mathrm{kD}$ band but not the red cell $60-\mathrm{kD}$ band, whereas serum $\mathrm{Ha}$ binds the red cell Ro $60-\mathrm{kD}$ but not the lymphocyte $60-\mathrm{kD}$ band. Serum St binds both the lymphocyte $52-\mathrm{kD}$ band and the red cell $54-\mathrm{kD}$ band. Almost all precipitating anti-Ro(SSA) sera that bind the 52-kD lymphocyte band also bind the red cell 54-kD band, but we have several anti-Ro(SSA) sera that bind the red cell 54-kD band that do not bind the lymphocyte $52-\mathrm{kD}$ band. Sera that bound only the $54-\mathrm{kD}$ or only the $60-\mathrm{kD}$ form in Western blot were used to immunoprecipitate the ribonucleoprotein and the as-

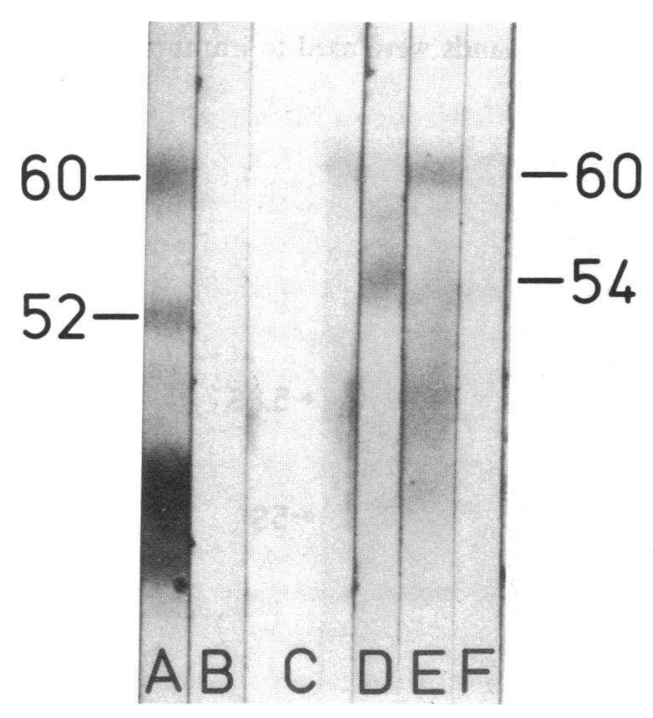

Figure 3. Western blot of CM-52 extracted lysates run on a $10 \%$ SDS-polyacrylamide gel under reducing conditions. Lane $A$ is a lymphocyte lysate with an anti-Ro(SSA), anti-La(SSB) serum. The strong lower band is the $45-\mathrm{kD} \mathrm{La}(\mathrm{SSB})$ protein. Lane $B$ is a lymphocyte lysate with a nonreacting serum. Lane $C$ is a fast green stain of the blot. Lane $D$ is a red cell lysate with an anti-54-kD Ro(SSA) serum. Lane $E$ is a red cell lysate with an anti-60-kD Ro(SSA) serum. Lane $F$ is a red cell lysate with a nonreacting serum. The molecular mass in kilodaltons is shown. 


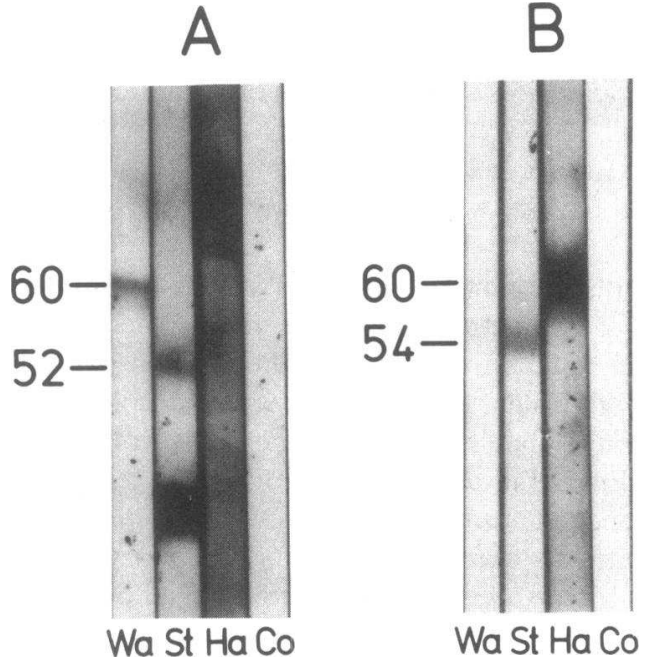

Figure 4. Western blot of CM-52 extracted lysates run on a $10 \%$ SDS-polyacrylamide gel under reducing conditions. $(A)$ Lymphocyte lysate. $(B)$ Red cell lysate. The reactivity with 1:100 dilutions of four sera are shown. Co is a nonreactive control. Wa reacts preferentially with the lymphocyte $60-\mathrm{kD}$ band. Ha reacts preferentially with the red cell $60-\mathrm{kD}$ band. $\mathrm{Ha}$ is an anti- $\mathrm{U}_{1} \mathrm{RNP}$ serum and also binds a $68-\mathrm{kD}$ band in lymphocyte extract. St is a serum that reacts with the lower molecular weight bands of both cell types, and also reacts in lymphocytes with the $45-\mathrm{kD} \mathrm{La}(\mathrm{SSB})$ band.

sociated hY RNAs were extracted with phenol/chloroform (Fig. 5). Also seen in this figure in lanes 2 and 3 are the red cell Ro RNAs brought down by serum 571, a rabbit antiserum prepared against affinity-purified human red cell Ro(SSA).

To ensure that the antibody in the serum that bound the RNA-associated protein was the same as the antibody that bound the two bands on Western blot, the affinity-isolated antibodies from the two bands were used to immunoprecipi-

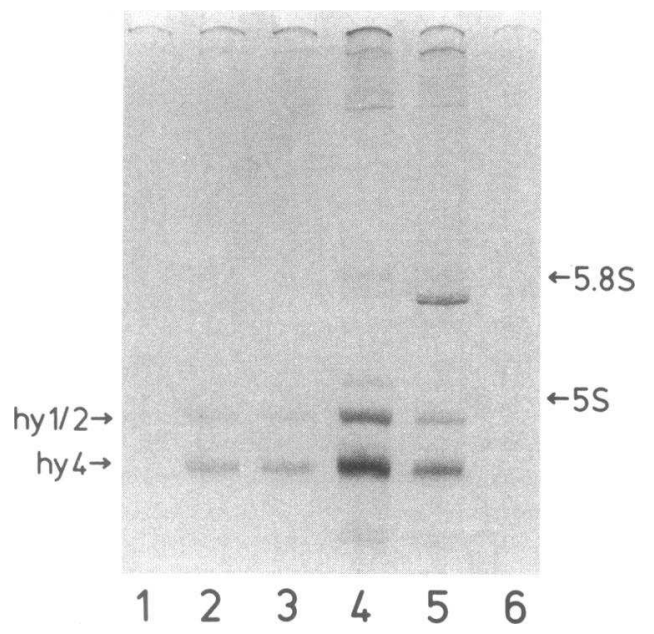

Figure 5. Silver stain of a $7 \mathrm{M}$ urea $10 \%$ polyacrylamide gel with RNA extracted from immunoprecipitates made from red cell lysates and prebleed (12/18/87) of rabbit 571 (lane 1 ), rabbit 571 anti-60kD RBC Ro(SSA), bleeding of 2/19/88 (lane 2), rabbit 571, bleeding of 2/22/88 (lane 3), human serum St that binds only red blood cell 54-kD band on Western blot (lane 4), human serum (Ha) that binds only red blood cell 60-kD band on Western blot, and normal human serum (lane 6). tate the particle. The associated hY RNAs were then extracted. The affinity-isolated antibody immunoprecipitated the same two hY RNAs (hY1 and hY4) from red cell lysates (data not shown), providing strong evidence that the antibodies in the serum that bound these two bands were anti-Ro(SSA). These affinity-purified antibodies also bound Ro(SSA) in nucleated cells evidenced by the recovery of hY4 and hY5 in extracts of immunoprecipitates using HeLa cells, but the gels were too light to detect the minor RNA species hY1 and hY3.

In summary, antigenic differences were detected between all four forms of Ro(SSA) using autoimmune sera. Sera from some patients were found to react exclusively with one and not with others, for all four forms 60 - and $52-\mathrm{kD}$ in the lymphocyte, and 60 - and 54-kD in the red cell (Fig. 4).

A sandwich ELISA was developed using a heteroantiserum raised in a rabbit against purified bovine Ro(SSA) (21). Using this assay we found the Ro(SSA) in red cell lysates was antigenically deficient to lymphocyte lysates that had equivalent amounts based on an ELISA using autoimmune sera (Fig. 6). The rabbit anti-bovine Ro(SSA) was thus able to detect differences in Ro(SSA) from the two cell types evaluated which had reacted in an equivalent fashion with human autoantibody.

Finally, two rabbit anti-red cell Ro(SSA) sera have been prepared that show the reciprocal result; lymphocyte Ro(SSA) is antigenically deficient to red cell Ro(SSA) in sandwich ELISA. Details of these sera will be reported elsewhere. Briefly, these sera bind only the $60-\mathrm{kD}$ red cell $\mathrm{Ro}(\mathrm{SSA})$ band in Western blot and immunoprecipitate Ro(SSA) RNAs hY1 and hY4 from red cell lysates (Fig. 5). These data further support anti-

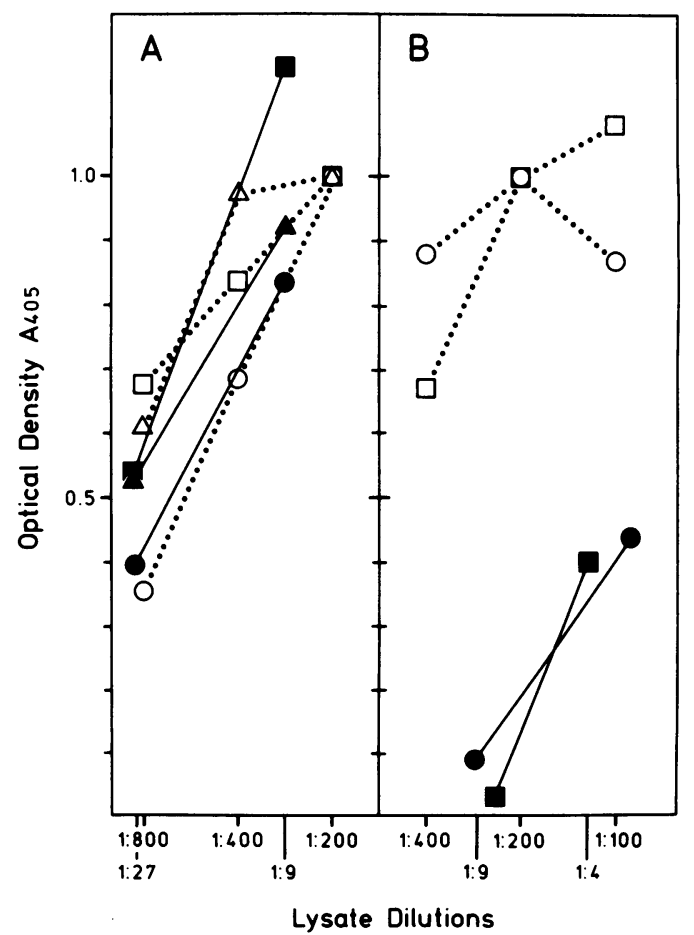

Figure 6. $(A)$ shows the $\mathrm{OD}_{405 \mathrm{~nm}}$ of dilutions of lymphocyte lysate (O, $\square, \Delta)$ and red cell lysate $(O, \square, \Delta)$ using a Ro(SSA) sandwich ELISA with autoantibodies. $(B) \mathrm{OD}_{405 \mathrm{~nm}}$ of the same two panels of lysates using a Ro(SSA) sandwich ELISA with rabbit anti-bovine Ro(SSA). Different symbols represent different experiments and emphasize the reproducibility of the results. 
genic differences between the four different types of Ro(SSA) protein described here.

\section{Discussion}

The major finding reported here is the identification of alternate forms of Ro(SSA) in the red blood cell. Others have used various methods to detect $\mathrm{Ro}(\mathrm{SSA})$ in a variety of tissues and cell types from different sources $(4,5,8)$. The use of a sensitive sandwich ELISA revealed detectable quantities of Ro(SSA) in crude lysates from red blood cells and lymphocytes. This activity was attributed to Ro(SSA) because concentrated extracts from red blood cells and lymphocytes precipitated with antiRo(SSA) in counterimmunoelectrophoresis, and the binding in ELISA was inhibited by more than $50 \%$ by affinity-purified bovine Ro(SSA). Additionally, Western blot analysis revealed two molecular forms of Ro(SSA) in the red cell. The $60-\mathrm{kD}$ band was partially inhibited by preincubating serum with purified $\mathrm{Ro}$ (SSA) from human spleen and both the 60- and 54-kD bands were shown to be Ro(SSA) by using the affinity-isolated IgG from the Western blot bands to immunoprecipitate the Ro(SSA)-associated RNAs from both red cell and lymphocyte lysates.

Comparing the ELISA activity of Ro(SSA) detected in lymphocytes using purified bovine spleen Ro(SSA) as a standard, weight units were calculated. The concentration of affinity-purified Ro(SSA) was determined by a dye binding assay (Bio-Rad Laboratories). The amount of Ro(SSA) in $10^{9} \mathrm{lym}-$ phocytes correspond to $200 \mu \mathrm{g}$ of purified Ro(SSA) or 2 $\times 10^{-13} \mathrm{~g} /$ cell. Using $60 \mathrm{kD}$ as the molecular mass of Ro(SSA), there are $2 \times 10^{6}$ copies of $\mathrm{Ro}(\mathrm{SSA})$ in each lymphocyte. If we assume that all the $\operatorname{Ro}(\mathrm{SSA})$ protein is associated with Ro(SSA) RNA, an estimate of $5 \times 10^{5}$ molecules of each Ro(SSA) RNA per cell is made because there are four Ro(SSA) RNA populations in lymphocytes (4). These results are similar to the $10^{5}$ copies per HeLa cell reported previously (4).

Because of the difference in antigenicity between lymphocytes and red cells, a similar calculation for red cells is not possible. The similarity between the Ro(SSA) in lymphocytes and the purified bovine Ro(SSA) suggested by the ELISA using the heteroantiserum makes it possible to calculate copies for the lymphocytes. However, the lack of a suitable standard, and the difference in apparent antigenic structure of the Ro(SSA) in the red cell, suggested by the difference in relative amounts in assays reflecting native and denatured forms of the antigen, do not permit a calculation of copy number.

Although differences have been noted in antigenicity and Ro(SSA) RNA populations across species lines $(4,5,8)$, we report a difference between cell types in the same species. Hendrick et al. reported no difference in the RNA populations associated with Ro(SSA) in erythroleukemia and B-lymphocyte cell lines from mice (4). The different findings here may suggest a species different, because murine lymphocytes are reported to have only two RNA species, compared with four for humans (4). Alternately, a difference in actively dividing neoplastic cells in erythroleukemia and the anucleated nondividing cells used here may play a role. There is not only a difference in the number of different RNA populations, but only one is of a similar size to that in lymphocytes (hY4). Whether this comigrating RNA is identical in sequence remains to be determined. Note also that the relative amounts of these two RNA species in red cells is similar to that seen with hY4 and hY5 in nucleated human cells. This difference in relative amounts also lends support to the existence of Ro(SSA) in red cells, as opposed to contamination from lymphocytes. These differing RNA populations may suggest heterogeneity of the Ro(SSA) protein.

Other investigators have reported different molecular weights for $\operatorname{Ro}(\operatorname{SSA})(9,14,22,24,25)$. Recently, there has been a report of two different molecular forms in the lymphocyte (26). Both forms have been described before, but the smaller protein was thought to be a degradation product (9). Ben-Chetrit et al. showed that antibodies from some SS patients would preferentially bind to the $60-\mathrm{kD}$ form, whereas others would only bind the 52-kD form (26). The two forms reported here differ from the two molecular types in lymphocytes. The common $60-\mathrm{kD}$ form in the two cell types appears to be antigenically different in that some sera bind the $60-\mathrm{kD}$ form in the red cell and not the lymphocyte and vice versa. This reciprocal antigenic difference shows that the two $60-\mathrm{kD}$ molecules are structurally different. The molecular weight differences previously thought to be the result of differential degradation are shown here to represent alternate antigenic forms in the lymphocyte and the red cell. The binding of different sera with different molecular forms may suggest a reason for the variability in the molecular weight of Ro(SSA) from 50 to $61 \mathrm{kD}$ that have been reported using anti-Ro(SSA) from different patients with different fine specificities $(9,14,23,25)$.

Reconciling the presence of multiple forms of Ro(SSA) with the finding of a single line of identity in immunodiffusion is a question requiring further investigation. Nonreducing SDS-polyacrylamide gels of the eluted precipitins from counterimmunoelectrophoresis showed the precipitins to be composed of a $60-\mathrm{kD}$ protein (data not presented). One explanation is that only the antibodies to the common epitopes are precipitating antibodies. The existence of nonprecipitating antibodies has been described in other systems (27). Whether such nonprecipitating antibodies exist in the sera of these patients is under study in our laboratory.

Additional evidence for the existence of separate gene products in red cells and lymphocytes is seen in the ELISA data with the two heteroantisera, the rabbit antibovine Ro(SSA) and the rabbit antihuman red cell Ro(SSA), respectively. The ability of these antisera to distinguish the two forms indicates two antigenically distinct groups.

Other evidence that was not reported here further supports the existence of different forms of Ro(SSA) in the red cell. We have observed a difference in susceptibility to chaotropic agents with Ro(SSA) from the two cell types. The antigen activity of $\operatorname{Ro}(\mathrm{SSA})$ from red cells as measured by ELISA is more easily destroyed by chaotropic agents than is Ro(SSA) from lymphocytes. Also, Ro(SSA) from red cells is antigenically less active than lymphocyte Ro(SSA) in native Western blots of isoelectric focusing gels when comparable amounts of Ro(SSA), as determined by ELISA, are used. This parallels the lesser antigenicity in red cell Ro(SSA) compared with lymphocyte $\mathrm{Ro}(\mathrm{SSA})$ in other assays reflecting native antigen structure such as gel diffusion, and Staphylococcus aureus-assisted immunoprecipitation. Western blots of SDS polyacrylamide gels show similar amounts of Ro(SSA) in red cells when compared with lymphocytes. These differential antigenic properties reflect the molecular differences among the Ro(SSA) proteins from these two cell types. 
In summary, we have presented evidence that red blood cells contain at least two Ro(SSA) particles and they are different from the two Ro(SSA) particles in lymphocytes. These differences include different associated RNAs in different relative amounts, different antigenic proteins detected by Western blot, and differing antigenicity in ELISA using heteroantisera. These differences in aggregate are best explained by the existence of separate gene products for the $\mathrm{Ro}(\mathrm{SSA})$ protein in lymphocytes and red blood cells. Whether these newly described forms of Ro(SSA) in the red cell, which are extremely active in the denatured state in Western blots, play a role in the pathophysiology of SLE and SS is a question for future research.

\section{Acknowledgments}

This work was supported by grants AI-24717, AI-21568, AR-31133, and AR-32214 from the National Institutes of Health, by a grant from the Biomedical Research Center of the Arthritis Foundation and also an Investigator Award from the Arthritis Foundation, by a grant from the Veterans Administration, by a grant from the College of Medicine Alumni Research Fund, and by a grant from the March of Dimes Birth Defects Foundation. This work is in partial fulfillment of the Ph.D. degree of Michael D. Rader, who is a Dean McGee Scholar.

\section{References}

1. Reichlin, M., and J. Harley. 1987. Antibodies to Ro(SSA) and the heterogeneity of systemic lupus erythematosus. J. Rheumatol. 14:112-117.

2. Harley, J., E. Alexander, W. Bias, O. Fox, T. Provost, M. Reichlin, H. Yamagata, and F. Arnett. 1986. Anti-Ro(SS-A) and antiLa(SS-B) in patients with Sjögren's syndrome. Arthritis Rheum. 29:196-206.

3. Kato, N., H. Hoshino, and F. Harada. 1982. Nucleotide sequence of 4.5S RNA (C8 or hY5) from HeLa cells. Biochim. Biophys. Res. Commun. 108:363-370.

4. Hendrick, J. P., S. L. Wolin, J. Rinke, M. R. Lerner, and J. A. Steitz. 1981. Ro small cytoplasmic ribonucleoproteins: further characterization of the Ro and La small ribonucleoproteins from uninfected mammalian cells. Mol. Cell. Biol. 1:1138-1149.

5. Clark, G., M. Reichlin, and T. B. Tomasi. 1969. Characterization of a soluble cytoplasmic antigen reactive with sera from patients with systemic lupus erythematosus. J. Immunol. 102:117-122.

6. Lerner, M. R., J. A. Boyle, J. A. Hardin, and J. A. Steitz. 1981. Two novel classes of small ribonucleoproteins detected by antibodies associated with lupus erythematosus. Science (Wash. DC). 211:400402.

7. Scopelitis, E., J. J. Biundo, Jr., and M. A. Alspaugh. 1980. Anti SS-A antibody and other antinuclear antibodies in systemic lupus erythematosus. Arthritis Rheum. 23:287-293.

8. Harmon, C. H., J. S. Deng, C. L. Peebles, and E. M. Tan. 1984 The importance of tissue substrate in the SS-A/Ro antigen-antibody system. Arthritis Rheum. 27:166-173.

9. Elkon, K. B., and L. Culhane. 1984. Partial immunochemical characterization of the Ro and La proteins using antibodies from patients with the sicca syndrome and lupus erythematosus. J. Immunol. 132:2350-2356.
10. Boogaerts, M. A., G. Vercelotti, C. Roelant, S. Malbrain, R. L. Verwilghen, and H. S. Jacob. 1986. Platelets augment granulocyte aggregation and cytotoxicity uncovering of their effects by improved cell separation techniques using Percoll gradients. Scand. J. Haematol. 37:229-236.

11. Catalano, M. A., E. H. Krick, D. H. DeHeer, R. M. Nakamura, A. N. Theofilopoulos, and J. H. Vaughn. 1977. Metabolism of autologous and homologous IgG in rheumatoid arthritis. J. Clin. Invest. 60:313-322.

12. Gorevic, P., F. Prelli, and B. Frangione. 1985. Immunoglobulin G (IgG). Methods Immunol. 116:16-18.

13. Nisonoff, A., F. C. Wissler, L. N. Lipman, and D. L. Woernsey. 1960. Separation of univalent fragments from the bivalent rabbit antibody molecule by reduction of disulfide bonds. Arch. Biochem. Biophys. 89:230-244.

14. Yamagata, H., J. B. Harley, and M. Reichlin. 1984. Molecular properties of the Ro/SSA antigen and the enzyme-linked immunosorbent assay for quantitation of antibody. J. Clin. Invest. 74:625-633.

15. Forman, M. S., M. Nakamura, T. Mimori, C. Gelpi, and J. A. Hardin. 1985. Detection of antibodies to small nuclear ribonucleoproteins and small cytoplasmic ribonucleoproteins using unlabeled cell extracts. Arthritis Rheum. 28:1356-1361.

16. Laemeli, U. K. 1970. Cleavage of structural proteins during the assembly of the bacteriophage T4. Nature (Lond.). 227:680-685.

17. Towbin, H., T. Staehelin, and J. Gordon. 1979. Electrophoretic transfer of proteins from polyacrylamide gels to nitrocellulose sheets: procedure and some applications. Proc. Natl. Acad. Sci. USA. 76:4350-4354.

18. Burnette, W. N. 1981. "Western blotting": electrophoretic transfer of proteins from sodium dodecyl sulfate-polyacrylamide gels to unmodified nitrocellulose and radiographic detection with antibody and radioiodinated protein A. Anal. Biochem. 112:195-203.

19. Krohne, G., R. Stick, J. A. Kleinschmidt, R. Moll, W. W. Franke, and P. Hausen. 1982. Immunological localization of a major karyoskeletal protein in nucleoli of oocytes and somatic cells of Xenopus laevis. J. Cell Biol. 94:749-754.

20. Olmsted, J. B. 1981. Affinity purification of antibodies from diazotized paper blots of heterogeneous protein samples. J. Biol. Chem. 256:11955-11957.

21. Wasicek, C. A., and M. Reichlin. 1982. Clinical and serological differences between systemic lupus erythematosus patients with antibodies to Ro versus patients with antibodies to Ro and La. J. Clin. Invest. 69:835-843.

22. Wolin, S. L., and J. A. Steitz. 1983. Genes for two small cytoplasmic Ro RNAs are adjacent and appear to be single-copy in the human genome. Cell. 32:735-744.

23. Mamula, M., O. Fox, H. Yamagata, and J. Harley. 1986. The Ro/SSA autoantigens as an immunogen: some anti-Ro/SSA antibody binds IgG. J. Exp. Med. 86:1889-1901.

24. McNeilage, L. J., S. Whittingham, I. Jack, and I. R. Mackay. 1985. Molecular analysis of the RNA and protein components recognized by anti-La(SS-B) autoantibodies. J. Clin. Exp. Immunol. 62:685-695.

25. Lieu, T. S., M. Jiang, J. C. Steigerwald, and E. M. Tan. 1984. Identification of the SS-A/Ro intracellular antigen with autoimmune sera. J. Immunol. Methods. 7:217-228.

26. Ben-Chetrit, E., E. K. L. Chan, K. F. Sullivan, and E. M. Tan. 1988. A 52-kD protein is a novel component of the SS-A/Ro antigenic particle. J. Exp. Med. 167:1560-1571.

27. Margni, R. A., and R. A. Binaghi. 1988. Nonprecipitating asymmetric antibodies. Annu. Rev. Immunol. 6:535-554. 